\title{
A MODEST PROGRAMME FOR THE IMPROVEMENT OF LAW TEACHING
}

\author{
JC Thomas*
}

In this article John Thomas looks at the efforts at Victoria University of Wellington over the past decade to improve law teaching and proposes a more comprehensive approach.

Most proposals for the improvement of legal education have little effect on the teacher's daily round. There are a variety of explanations for this. Frequently, the discussions are too general, too high flown or too concerned with structural or curriculum problems. Generally, there will be no follow-up programme which ensures practical implementation of even those ideas which are accepted as worthwhile.

The discussions most likely to have practical impact are those which a particular law school arranges for itself in order to deal specifically and realistically with what is currently done and what can be done in that school's own courses. They need to be continuing discussions based on trial and error in the classroom. The crucial need is for the law school to adopt a comprehensive programme which will encourage and facilitate those class-room experiments and continuing discussions.

At Victoria over the past decade there have been many worthwhile teaching and assessing experiments and many discussions about them. They have been inspired and developed by many people, both staff and students. This paper draws upon this experience

* Senior Lecturer in Law, Victoria University of Wellington. Dean of the Faculty of Law, Victoria University of Wellington, 1973-6. The article was first published at (1978) 9 VUWLR 405.

* This article is a revised version of a paper originally presented at the 1975 Conference of the Australia and New Zealand Association of Law Students. I am particularly obliged to Dr R L Congreve who read a draft of the original paper and insisted that most of the cliches be deleted. I am also obliged to Professor K J Keith, the present Dean of the Faculty of Law at this university for helping with its revision and encouraging me to publish it on this occasion.

Many of the views expressed in this paper are the result of formal and informal discussions over the years with various members of the Law Faculty at Victoria University of Wellington and the consideration of various written reports submitted to the Faculty. 
in an effort to formulate a programme which could contribute to the continued and systematic improvement of Victoria's teaching and assessing programme.

The duty of the law school is to create an environment which:

- encourages teachers to think more about the goals which they are seeking to achieve and the ways of achieving them;

- gives teachers a better idea of the difficulties to be overcome and some positive examples of the ways in which they can be overcome;

- enables them better to assess the extent to which they are successful in achieving their stated goals;

- encourages them to devote a higher proportion of their time to improving teaching and assessing;

- encourages them to share teaching and assessing experiences and exchange views about those topics.

\section{GOALS OF THE LAW COURSE}

The law school must start its own contribution to the improvement of teaching by defining its goals. These goals should reflect the views of staff, students and practitioners. As an example at Victoria there has been a general acceptance of the following statements ${ }^{1}$ about legal education.

Most law graduates will eventually go into private practice. The Law Faculty recognizes that it has a major obligation to provide a kind of education which equips its graduates for such a career. This does not, however, mean that it cannot cater for students interested in other careers. Nor does it mean that a law course should be an apprenticeship course. A narrow technical approach, one that fails to consider law in its social context, has no place in a University and, in any event, is of little use to anyone who hopes to practise law. Technical legal competence is essential but by itself it is not enough.

$\cdots$

If lawyers are to contribute to and cope with a rapidly changing society they need a general liberal education which encourages them to think for themselves and helps them to understand something of the role of law in society. They also need a variety of professional skills and knowledge.

1 The Faculty of Law 1978, 2-4. These pages in this handbook for first year students contain contributions from a succession of Deans. 
If the law school's courses meet these two needs "then they provide an education of use and interest to those who do not intend to practise law as well as to those who do".

[A] law course should develop the following inter-related qualities: ${ }^{2}$

(i) Understanding of the role of law in society:

["Law not only operates to order society as we know it. It is also an affirmative force in the process of orderly social change. Law is not static. A person who understands the law and the processes by which it functions is in a position to make truly important contributions to society. By adapting and using the teachings of the past rather than merely echoing them, he is able to find solutions to new social problems as they arise. ${ }^{.3}$ Accelerating changes in society, its values and technology will lead to rapid changes in the law. This means that the study of law cannot realistically be confined to the rote learning of rules.

In order to understand those changes and, to help initiate some of them, a lawyer needs a general liberal education. For example, the $\mathbf{3 0}$ arts or science credits which students take at the beginning of their law course are intended to broaden the base of their understanding and to give them some introduction to the techniques and approaches of other disciplines... In addition, law teachers are coming to recognise the need to draw upon the insight and techniques of other disciplines in the teaching of law subjects themselves and in order to ensure that law graduates are able to participate in and understand future development in the law. Again, this inter-disciplinary approach reflects the belief that law is not some "closed system obedient to some secret arcane process but is intimately bound up with the society which it regulates"]. ${ }^{4}$

(ii) Knowledge of institutional environment:

The knowledge of the role of Parliament, local bodies, courts, officials, agencies, and other public or private institutions, their uses and the limits of their effectiveness.

\section{(iii) Analytical skills:}

The capacity to analyse legal materials, i.e., to read and understand Acts of Parliament, judicial decisions, and other legal materials; the capacity to analyse a problem, i.e., to separate the material facts from the immaterial facts, to survey the problem from many perspectives, to apply relevant legal principles, policies and rules to those facts.

2 The Faculty of Law, op cit. The listed qualities are taken with only minor modification from a report on legal education prepared for Osgoode Hall Law School of York University and entitled Report of the Long Range Academic Policy Study Group (1974) 28.

3 Iowa Law School Announcement.

4 Osgoode Hall Report, op cit. 


\section{(iv) Research skills:}

The capacity to find the relevant law by use of the library and to find other information which is needed.

\section{(v) Communicative skills:}

The capacity to listen and to argue and to write effectively.

(vi) Knowledge of the law and its practical implications:

The knowledge of some of the important parts of the law, sufficient knowledge to enable tentative diagnoses of many problems so as to indicate the direction of further analysis and research.

(vii) Professional knowledge and skills:

The capacity to draft court documents and conveyancing documents (e.g., documents giving effect to the buying, selling, mortgaging, and leasing of property), the capacity to anticipate and circumvent legal or factual problems and to help clients organise their affairs to full advantage within the law: a knowledge of office and courtroom practice...

(viii) Public Responsibility:

A sense of professional responsibility to clients, to courts, and to the legal system as a whole.

\section{BITING THE BULLET}

Although individual emphasis may differ, general goals of this kind are unlikely to generate much controversy among law teachers or students. This lack of controversy can be a disadvantage as well as an advantage. Teachers accede easily to such a list of goals because they sound good, are very general and no-one really expects their adoption will require any substantial change in the way in which individual courses are taught. The acceptance of some general goals will not in itself lead to any increase in the number of teachers who in preparing for class ask themselves "In taking this lecture, what particular goals, other than a mere exposition of the relevant rules, am I seeking to achieve?" The real need then is to get teachers to bite the bullet.

\section{A Course Papers}

The best way of getting teachers to focus on these goals is to ask those involved in lecturing or tutoring in a particular course to prepare a paper about their course ("a course paper"). This paper should do three things. First of all, it should identify the particular goals which the teacher wishes to achieve in that course. Secondly, it should describe and give specific examples of the means by which he or she goes about achieving these goals. Thirdly, it should give some estimate of the success of the various means used. This estimate 
should include some discussion of the type of examination and other methods of assessment used in the course and of the level of the students' answers. The results of course evaluation questionnaires might also be helpful. ${ }^{5}$ The paper could be distributed to all members of the Faculty and then discussed in some appropriate forum.

The preparation and discussion of a course paper should be helpful to those who prepare it, to other teachers who read or discuss it and to the law school itself. In addition, the distribution of the paper or a modified version of it to students could help their understanding of their courses.

For the teachers concerned, the first advantage of preparing the paper is that they are forced to think more carefully about the educational goals of their course and to define them more precisely. A good number of teachers who had to prepare such a paper might well find that they had never before really thought very clearly about their course goals. They might also see that with a slight re-orientation of material or change of approach additional goals could be achieved.

The teachers would derive a second and even more important advantage from the need to think about the specific means by which they seek to achieve those goals. Again, many teachers might find that they have never previously developed any specific strategies which they can use in order to direct individual lectures towards one or other of their accepted goals. There is a tendency to assume that these goals will be reached by some vague osmotic process.

A third advantage which the course paper brings to those who prepare it stems from the need for them to make some written assessment of the effectiveness of their teaching methods and to identify the reasons why certain methods have proved successful while others have failed.

Fourthly, by reviewing their assessment processes and their students' responses to them, teachers might well feel the need to alter the level and manner in which they teach and assess their courses.

It can be argued that even without the need to prepare a course paper teachers already do all these things for themselves. But is this universally true? Because of other more immediate demands on their time and possibly from a subconscious desire to preserve selfimage, many teachers may never get round to making such a review of their courses.

The need to prepare a course paper ensures that the teachers do not lose sight of the need to make an appraisal of their aims, methods and effectiveness. The fact that the paper will

5 Note however, the concern for confidentiality about the results of course evaluation questionnaires discussed infra at 414-416. 
be read by colleagues makes it more likely that the appraisal will be specific enough to be useful.

The advantage which course papers bring to other members of the teaching staff is that they provide a source of ideas from which they can draw as they think fit. Knowing that specific methods have enabled their colleagues to achieve certain goals might well reactivate some teachers who, for want of positive proof, have rejected these goals as impossible of attainment.

Course papers will enable the law school to make a better appraisal of the extent to which it is achieving its general goals. Obviously, every course does not attempt to achieve all of the general goals, adopted by the law school. Once papers have been presented for all courses, a review of them would almost certainly show that some of the law school's general goals receive little, if any, attention in any courses at all. How many courses really attempt to develop "Research Skills" or "Public Responsibility"? With regard to "Professional Knowledge and Skills", do many courses deliberately set out to develop "the capacity to anticipate and circumvent legal or factual problems and to help clients organise their affairs to full advantage within the law"? Everyone may agree that these are vital goals, but is anyone doing anything about achieving them?

A comprehensive set of such course papers could also reveal that some important areas of law are not taught in any course. The teachers of Contract may hope that equitable remedies are taught in Equity. Those in charge of Equity may assume that equitable remedies are covered in Contract. Do the teachers of either course check that their assumptions are correct? Who knows whether fundamental property concepts are taught in Land Law, Equity, or Commercial Law and Personal Property? Is there any course which deliberately attempts to build upon the elementary introduction to statutory interpretation given in Legal System? From time to time, problems of this kind are discovered largely by chance. Presentation of a series of course papers would enable a more methodical review to be made.

Course papers can also play a vital part in the law school's review of its examining standards. They can help reveal whether there is any justification for the differences in the pass rates in various subjects. They can contribute to the development of a greater consistency of assessing standards throughout the Faculty.

\section{B Discussion of Course Papers}

The value of course papers would be greatly enhanced if they were discussed in some appropriate forum. Generally, the appropriate forum might be a full Faculty meeting. However, additionally, or alternatively, some courses might be discussed at smaller meetings, e.g., there might be meetings of all those involved in the teaching of the compulsory "second year" subjects (Contract, Torts, Criminal Law, Constitutional Law), or all those teaching subjects with related subject matters (the "commercial" subjects, Contract, 
Commercial Law and Company Law and Partnership or the "property" subjects, Land Law, Commercial Law and Personal Property, Equity), or those teaching by similar methods (the "socratic" courses). Whatever the forum, it is desirable that, if possible, someone from the University's Teaching and Research Centre or Education Department should also take part.

Such meetings provide an opportunity for an exchange of views and experience on an area of vital importance to all participating. It is an article of faith in relation to academic matters that the exchange of ideas is worthwhile in itself. It is one of the reasons why teachers go to conferences. It is the justification for the "case method" classes, seminars and tutorials which they prescribe for students. Why then is there inevitably some reluctance to take part in discussions about teaching? A number of arguments are invariably paraded. Many can be refuted on the simple ground that they do not relate to the discussion of the course papers now proposed.

"Discussions on teaching never get anywhere". This is an argument based on evidence (frequently hearsay) of unsuccessful meetings in the past. The problem with many discussions about teaching is that they have tended to be too remote from what is likely to be done in the average teacher's next class. For example, reviews of the curriculum and the degree structure will not in themselves overcome teaching problems. A subject not well received by students may be shunted from the fourth year to the third year to the second year of the course in an effort to reduce consumer resistance. Other subjects may be divided up, then amalgamated, only to be re-divided again. Yet despite all these structural changes, the teaching problems remain. Not all discussions of the curriculum and degree structure are unproductive. However, the examples just mentioned are real enough to cause some teachers to be disenchanted with meetings about courses. This disenchantment is increased by the fact that most members of the Faculty do not have any involvement in the courses under discussion. The majority have to take part in or listen to a protracted debate knowing that, whichever way it goes, the outcome will not have any direct effect on them.

Other discussions on legal education may be based on radical proposals for change often expressed in deliberately provocative terms. The issues become lost in the battle to trim down the extravagance of the language. In addition, some proposals will be dismissed as desirable but unrealistic. They ignore the limitations imposed by classroom realities or the law school's lack of teaching and financial resources.

Even discussions on teaching techniques tend to be too general or too superficial. Teachers are exhorted to be interesting or practical or relevant to contemporary society. But they do not need to be told this. What they do need is some specific proposals or examples which can help them to achieve some of those things in the class which they have to give at 9.00 a.m. next Monday. The cry is "don't tell me to give lectures that are practical: tell me how to be practical". Meetings with teachers from other disciplines can often bring insights for law teachers but, unfortunately, they can also cause frustration if the group's 
attention becomes bogged down in some difficulty peculiar to one particular discipline. Alternatively, in seeking to avoid this danger the discussion may become so general that it is of no practical use to any disciplinary group at all.

Again, these examples are not an attempt to discredit discussions about the curriculum, degree structures, long-term goals, general goals or problems common to all disciplines. The point is that even if some discussions of these other types have failed in the past, this does not mean that discussions of the type now proposed will also be unsuccessful. Discussions based on course papers should overcome most of the difficulties just described. By focusing on specific and detailed means by which law teachers can make a better job of what they are already doing, such discussions should provide something of use to all those who take part.

Another argument against holding discussions on courses is that teachers already waste too much of their time at meetings. Instead of talking about teaching, they would do better if they were to "get on with it". There are three replies to this. First, the meetings which now proposed are not a substitute for "getting on with it". Rather they are an incentive to get on with it first and then to report and discuss what has been achieved. Secondly, it is not easy to accept that if these meetings were not held teachers would use the time to work on, assess and discuss their courses. Thirdly, if law schools do have too many meetings, then let some of the other meetings be reduced in order to make way for those about teaching.

A third argument is that such meetings involving the discussion of individual teaching methods may lead to hurtful personal criticism. Experience at Victoria already shows this is not a significant danger. If anything, the value of the discussion has been diminished by an excessive concern to avoid giving offence. As a result, the discussions can become too bland to be informative. Good chairmanship can easily keep the discussion within appropriate bounds. In addition, it is important that the preparation and discussion should not be seen as some isolated "High Noon" for a particular teacher. It is an essential part of any effective programme for the improvement of teaching that the law school creates a supportive atmosphere in which people can acknowledge their failures or have them pointed out by others in the expectation that they will receive encouragement and help, not condemnation. Private conversations and "sitting-in" on lectures are two things which can avoid the notion that the discussion of a course paper is the be all and end all of the Faculty's interest in a particular course or teacher.

\section{Specific Lessons from the Past}

Victoria has some experience in the review of courses and in the presentation and discussion of papers having some of the features of the programme now advocated. In 1969, all courses were reviewed at a series of informal meetings attended by those involved in teaching the particular course under review and the relevant Head of Department. Papers of various kinds were presented at these meetings. In the period 1976 to 1977 the courses in 
Legal System, Law in Society, Contract and Constitutional Law were reviewed at Faculty meetings at which course papers were presented. The Contract and Constitutional Law papers addressed themselves to examining standards as well as teaching goals and methods. During the period 1976 to 1978 the law school had discussions with representatives of the legal profession about practical legal education. Various papers were discussed. One by Mr E C Williams provides an excellent model. ${ }^{6}$ At a conference of New Zealand Law Teachers held in November 1977 there was some discussion of courses and teaching methods. Some written material about course content was presented. This experience encourages the belief that the programme now advocated is worthwhile and feasible but requires considerable effort and organization. It provides some specific lessons which should be emphasised:

- The programme can succeed only if there is a whole-hearted commitment to it by the law school and its leadership in particular. It must be given the highest possible priority by the law school in its institutional activities and by all staff members in their individual academic activities.

- A firm and realistic timetable must be established for the presentation of course papers. The necessary academic momentum must be maintained so that the programme does not either become fragmented or, worse, grind to a halt.

- The programme must be a continuing one. It is essential that there should be some system for effective follow-up; changes in course goals should be notified.

- Without turning the programme into some competition for promotion, teachers should be encouraged to present papers of a quality which they regard as exemplifying their skill and interest in teaching.

- Every course paper should display the qualities of scholarship expected of an article submitted for publication. The presentation of a course paper should not be seen as some administrative formality requiring a two page list of topics and case-names embellished with a generality or two. The Dean should treat a shoddy course paper in the same way as a law review editor would treat a shoddy article.

- Teachers asked to prepare a course paper should know exactly what is expected of them. It is important that the first few papers presented for discussion should be of a standard which enables them to be used as models for later papers.

- There should be active participation in discussion of course papers by as many Faculty members as possible. In general, each course paper should be discussed at a

6 Williams "Practical Training of Lawyers" [1977] N.Z.L.J. 391. 
full Faculty meeting at some stage. This does not mean that it should not be referred to some smaller group, at some earlier or later stage.

- The greatest danger about discussion of course papers is that they will be too bland rather than that they will be too acrimonious. It is essential that discussion should be candid, with all questions, doubts, criticisms, differing approaches or evaluations fully aired. The atmosphere should be supportive but frank.

\section{Evaluation}

Two most effective means of improving teaching would be:

- to help teachers make a more realistic evaluation of the effectiveness of their current teaching practices;

- to provide illustrations of approaches and techniques which, with adaptation, they might use to improve their teaching.

Good feedback is vital to good teaching. Just "getting in there and doing it" is not enough. Students in Psychology I at Victoria used to be told that the adage "practice makes perfect" is true only if you can see the results of your actions as you do them. The lecturer gave the illustration of playing darts in the dark. If you practise at darts then you gradually improve. You learn to adjust your aim and your throwing technique as you see how close to the bullseye you get with each successive throw. However, if you practise with the light out, then you will never improve. Since you cannot see where your dart lands, you never know whether or not it is necessary to make some adjustment in your aim or technique. Some teachers find it more comfortable to teach with the light out. True, it is these days virtually impossible to avoid getting some feedback on any teaching one does. But this feedback tends to be fragmented and incomplete. An improvement in the quality of the feedback would correspondingly increase teachers' ability to improve their teaching methods.

Until recently, teachers' assessment of the effectiveness of their teaching methods was largely subjective: a visceral response to such things as

- their own performance ("I felt it was going over well");

- student reaction in the lecture room (which is perhaps likely to be more reliable in those classes where there is substantial class discussion);

- student reaction in tutorials;

- student answers in examinations and exercises;

- private discussion with students. 
Nowadays, teachers can or should also have available to them some more objective assessments of their performance:

- opinions of other lecturers or tutors in the subject;

- opinions of other teachers who have read their course paper and/or attended their classes;

- opinions of a member of the University's Teaching and Research Centre or Education Department who has attended their classes;

- course evaluation questionnaires answered by all students in their class.

These objective assessments need not replace the existing subjective ones. The two forms of assessment are complementary.

\section{E Course Evaluation Questionnaires ${ }^{7}$}

Course evaluation questionnaires of various kinds have been used at Victoria for many years. However, in August 1972, the Faculty began to debate the desirability of developing a standardized questionnaire. It was not until July 1978 that the Faculty adopted a recommendation for the annual administration of a standardized questionnaire in all law courses. The Dean and the Chairmen of the two Law Departments were asked to accept responsibility for the administration of the questionnaire.

Throughout the Faculty's prolonged debates on course evaluation questionnaires, there was a continuing, albeit diminishing criticism of them. On reflection, the criticism tended to involve little more than the knocking down of men of straw. Most criticisms could be encapsulated in the non-sequitur "questionnaires are not perfect: therefore they are not worth having". The critics harped about examples where the students' response was indecisive. There were stories about "half the class saying I talk too quickly and the other half saying I talk too slowly". If such instances do occur, they may at worst render the responses to that particular question unreliable. But an indecisive response to one question does not significantly reduce the usefulness of clear-cut responses to other questions. If eighty percent of the class say the teacher is boring, then he is a fool if he attempts to discount that response by pointing to the fact that the response to some other question was indecisive. If a teacher, whose principal aim is to teach the practical implications of law, finds that seventy percent of his class do not believe he has achieved his goal then at the very least he needs to consider what he could do to make clearer to his students just what the practical implications of his subject are.

7 I am indebted to a report on Course Evaluation Questionnaires prepared for the Faculty of Law at Victoria University of Wellington by Mr L. H. Atkins in 1972. 
One can believe in the usefulness of course evaluation questionnaires without going to the extreme of saying that teachers should always feel obliged to do what their classes tell them to do. The devotees of the case method may be unlikely to yield to student demands that they should revert to giving lectures but they might want to consider whether they ought to give their students some additional information in order to prime the pump a little. They might seek advice about whether they are too abrasive or intimidating. At least, they might ask themselves whether they could better explain to their class the purpose and value of the method they use.

Of course, student responses to questionnaires are better at revealing weaknesses than in overcoming them. Still, the inability to solve the problem does not destroy the usefulness of revealing that a problem does exist. Once they find out that a problem exists, teachers may be able to solve it for themselves or get help in solving it from their colleagues. But, until they know what their problems are, they are unlikely to improve.

Under the programme now proposed, an adverse course evaluation should not only prompt teachers to make their own review of their teaching methods but should also encourage them to ask one of their law colleagues or a member of the Teaching and Research Centre for advice or even to sit in on one of their lectures.

Even more animated was the Faculty's debate on the proposal that the results of such questionnaires should be revealed to the Dean, Chairmen of Departments and the Faculty's nominee on appointments committees in order to assist the university in considering promotions and appointments. Some feared assessing of teaching ability would become a mechanical or arithmetical matter. However, most arguments against the use of questionnaires for this purpose tended in substance to amount to little more than a warning against regarding the student response as determinative. There was concern that the teacher who is inexperienced or experimenting with new teaching methods, should not be condemned because of adverse evaluation in a single year. Teaching methods which are unpopular with students may nevertheless be educationally desirable. Methods which are popular with students may be educationally undesirable. However, it is possible to concede that student opinion can never be determinative in itself without being forced to condemn it as insignificant or irrelevant.

There is no reason to believe that a student evaluation is the one piece of information which those responsible for appointments and promotions cannot be trusted to treat for what it is worth. Why should anyone expect them to give it disproportionate weight? The response to the questionnaire is one piece of information, one opinion, to be balanced against other pieces of information and other opinions about the teacher's ability. This again demonstrates the value of having a comprehensive programme for improving teaching. If the law school adopts the kind of teacher training programme advocated in this paper then the Dean and Chairmen of Departments will be able to call upon their own first-hand 
knowledge about a teacher's ability and the opinions of their colleagues in deciding what weight should be attached to student opinion in a given case.

Ultimately, the Faculty decided that the results of the questionnaire should be available for use in promotion and appointments processes.

Further controversy related to the view held by many students and a significant number of teachers that the results of the questionnaire should be made available to all interested students. This was advocated on a number of grounds:

- it is anomalous that students should be prevented from knowing about opinions which they themselves have expressed;

- the results of the questionnaire would provide a more reliable basis for students to choose the optional courses they wished to take than the present basis which consists largely of intuition and the possibly unrepresentative opinions of a few friends;

- it would improve the quality of teaching by making it more difficulty for teachers to ignore student criticism;

- students are cynical about the value of questionnaires when they have no means of knowing the results. Some regard questionnaires as no more than a confidence trick.

The first of these grounds was largely rhetorical. The third and to some extent the fourth would be adequately dealt with by the kind of programme which is outlined in this paper. The second ground was, however, a very substantial one requiring a more detailed answer. The counter arguments included:

- there is an essential difference between making student evaluations available to those engaged in appointments and promotions and making them available to students. In the former situation, the people receiving the information are in a position to exercise some independent judgment about the weight to be attached to the student evaluation and to know of special factors (e.g. experiments with new teaching techniques) which might have affected the teaching of a course in a particular year. To release the evaluations to students who are not in a position to exercise this kind of independent judgment would be to allow those evaluations an unduly great influence. Students would attach much greater importance to the results of an evaluation than they would to the casual opinions of a few of their friends;

- disclosure of evaluation results to students not in a position to exercise any independent judgment about them is much more likely to discourage experiments with new teaching methods and to lead teachers to "pander to the ratings", than would be 
the case if disclosure was confined to the Dean, the Chairmen of Departments and the lecturer in charge of the subject;

- teachers might feel reluctant to make changes necessary to meet published criticism lest they appear to be capitulating to pressure;

- publicizing student evaluations could lead to tension between staff and students;

- making adverse evaluations generally available would cause an embarrassment to the teachers concerned which is quite disproportionate to the advantages which might be achieved. There is an analogy with the way in which individual examination marks are not publicly disclosed in order to save students from unnecessary embarrassment;

- the arguments against publicizing student evaluations are sufficiently strong to make it desirable that any move to do so should be deferred until it is supported by a substantial majority of teachers. Progress in any teacher training programme is to a large extent dependent on the goodwill of those concerned. The effectiveness of the programme will be endangered if adequate respect is not shown to the views and feelings of a sizeable minority. Too much pressure will lead to recalcitrance, not reform.

In the end, the Faculty decided that the results of course evaluation questionnaires should not be made generally available. Notwithstanding this, the annual administering of questionnaires in all law courses and their use in promotions and appointments will be important influences in improving the quality of teaching.

\section{E "Sitting-In" on Lectures}

Occasionally, law teachers at Victoria "sit-in" on other teachers' classes. Most often, it will be done by tutors in a subject seeking to keep abreast of new material. There is enough experience of "sitting-in" to show that it need not disrupt the class or place undue strain on the participants.

It would be a major contribution towards improving teaching if the law school were to develop a tradition whereby it became commonplace for teachers to "sit in" on each other's classes. This contribution will be particularly enhanced if it becomes an established practice for the teachers involved to have a candid and constructive discussion afterwards. Both the strengths and the weaknesses of the lecture should be identified and analysed.

Visits to other teachers' classes might take three forms. First of all, there might be an informal arrangement between two or three teachers that they would visit each other's classes. After the class, they might have a talk together over coffee. Bland generalities should be avoided. The discussion must be specific. "I liked the way you did that particular 
thing". "I thought their attention wandered when you spent so much time on that particular aspect". "What were you after when you asked about something else?" "I have a different way of dealing with that problem".

Secondly, there might be organised visits by a large number of staff to a nominated lecture. These might be linked with presentation and discussion of course papers. Staff visiting the lecture would know in advance what the teacher's aims were and how he or she expected to go about achieving them. After the lecture there could be a general discussion of what had in fact been achieved in the lecture, of the problems encountered and of alternative means of overcoming them Some students, both present and former members of the class, could also be invited to take part in such a meeting although in order to facilitate discussion it may be desirable to keep the group a reasonable compact one.

A few years ago, a law teacher at Victoria held a discussion of this kind. There was a moderate attendance of other staff members at the lecture and the later discussion. There were also a dozen or so students present at the discussion. It did not bring about the millenium but it was a most promising experiment. Certainly, it demonstrated that it was possible to have such a discussion without rancour or personal embarrassment. If anything, people were a little too inhibited in their criticism, but this is something which can be overcome by experience.

Thirdly, a representative of the University's Teaching and Research Centre or Department of Education might be invited to attend individual classes and to have a private discussion with the teacher afterwards. In addition to this private discussion, the representative should also take part in the more formal group discussion just described.

Visits of these kinds could make a major contribution towards the improvement of teaching. They improve teachers' ability to evaluate their own performance; they enable teachers to get constructive and specific advice from their colleagues; they provide the visiting teachers with a model; they provide a good basis for discussion about course papers and teaching in general; they provide first-hand knowledge to those influential in promotions and appointments.

\section{G No One Way}

It should be made clear that the purpose of these visits and discussions and the proposed teaching programme as a whole is not to convert all teachers to the same method of teaching.

Neither students nor teachers would benefit from such wholesale conversion. On the contrary, it is important that students should be exposed to a range of approaches, a variety of teaching techniques. 
A recent Canadian book in which twenty-three outstanding university teachers describe their aims and methods is aptly titled, Teaching in the Universities: No One Way. ${ }^{8}$ Basing discussions on particular lectures, which may provide a model for other teachers, can be a particularly effective means of informing other teachers about the different approaches and techniques which are open to them In the ultimate, however, each teacher must choose for himself or herself the approach and techniques which best suit his or her subject, his or her aims, his or her personality and his or her interests. The purpose of such a programme is not to make all teachers conform to the one approach but rather to show them that there are an infinite variety of approaches. One very experienced teacher of teachers ${ }^{9}$ says these sessions provide a "smorgasbord of ideas" from which each person may choose according to his or her taste and personality. A teacher can inspect the fare at the smorgasbord without obligation to buy. However, few law teachers could emenge from a programme of this kind without coming across some ideas which they thought could be adapted for their own use.

\section{ACADEMIC FREEDOM}

The principle of academic freedom is vital. It protects the teacher from political interference. It enables "one to teach what one believes rather than a prescribed doctrine, to speculate and investigate as the spirit moves one and to publish without restraint".10

Nothing in this paper impinges on academic freedom. Nevertheless, it is desirable to refer to it because few discussions of programmes for the improvement of teaching and assessing proceed for long without there being some incantation of the magic phrase "academic freedom". The principle is too important to allow it to be endangered by its constant invocation in inappropriate contexts. Academic freedom is conferred not for the personal benefit of the teacher but for the general good. Moreover, like all freedoms it has its limits: ${ }^{11}$

It does not mean freedom to neglect students who have been committed to one's care, to refuse to teach the subject for which one has been appointed or to participate in necessary academic activities which involve co-operation. It does not mean that once a man has been appointed he can do just what he likes.

There is no academic freedom to be incompetent. There is no academic freedom to be uncooperative. There is no academic freedom to fail students by applying idiosyncratic standards. Academic freedom confers no immunity from reasonable persuasion or reasonable criticism.

8 Noted in (1975) 18 A.C.U. Bulletin of Current Documentation 5-6.

9 Mr J. J. Shallcrass, Reader, Education Department, Victoria University of Wellington.

10 Robbins Of Academic Freedom (London, 1966) 5.

11 Idem. 
Regardless of the precise limits of academic freedom, teachers can expect that in discussions about teaching their colleagues and students will show due respect to their wish to do things in their own way, even though the majority believes it to be an inferior way. Teachers should not be harassed because their teaching approaches are different or because they seek to give rein to their individuality.

In setting up a teacher training programme, law schools must be alert to the dangers of "academic fascism". The individual is entitled to respect for his views and even some concessions to them However, the need to be alert to these dangers should not paralyse those who seek to make modest innovations in order to improve legal education.

The present references to the limits of academic freedom are made solely in order to get rid of a concept which should be seen as an irrelevant one in this context. This should not give the impression that the programme now advocated should be based on coercion. On the contrary, the programme can only be successful if the teachers want it to be successful. Cooperation, mutual esteem and respect for differences are essential. In the development of people's attitudes towards such a programme, the leadership of senior members of the Faculty should be particularly influential. If they demonstrate their belief in the importance of teaching and will give active support to the programme its implementation and success is assured.

\section{COMPETING DEMANDS}

The adoption of the programme now advocated will take up time which might otherwise be used on research and publication. It will affect teachers' prospects of promotion and appointment. The law school needs to adopt a stance on these problems which reinforces the proposed teaching programme. It needs to consider its attitude to some issues which will ultimately be decided by the university rather than the law school itself.

\section{A Teaching and Research}

Universities have always assumed that teaching and research were inter-related activities, each nurturing the other and each drawing substance from the other. Today, however, some staff and student critics talk as though research, far from being the indispensible ally of teaching, is its implacable opponent. This concern is not confined to a few radical or disgruntled teachers or students. Sir Frederick Dainton, then Chairman of the University Grants Committee in the United Kingdom, has said this: ${ }^{12}$

... I do know that most [university teachers] have never received in their careers any kind of preparation for the tasks of encouraging student learning and assessing students' progress, nor

12 Dainton "Failing to Match the Dreams of the Angry Young", The Times Higher Educational Supplement, London, 9 August 1974, p. 12. 
will they do so if they look for their rewards and promotions through achieving status accorded to them by research.

I have made pejorative references to research as being almost the enemy of teaching and you will expect me to justify them. The inter-relationship of teaching and research has long been embedded in mythology. At one end of the spectrum it is undeniable that the good and conscientious teacher is often a better teacher if he is also researching on important problems. It is not so much that better knowledge is transmitted as that this matter is discussed with students in an inquiring manner. The teacher's interest in his subject matter is transferred and even students rank the "enthusiasm" of teachers as an important incentive to their own learning.

But does the research that is now done in science departments of universities "quicken the mind" of either teacher or student? Or is it merely dull inquiry designed to get the credit of another trivial publication and enhance promotion prospects? Is there such a thing as bad research as well as good, and is it both the enemy of the good and mind-constricting, rather than liberating? Can even good research be so demanding on the time of the researcher and can the pressure of the high status attached to doing it be so great that the balance of effort between teaching and research is distorted? Have we allowed the numerically successful narrow researcher to be more prized in our universities than the gifted and devoted teacher who offers his students that most priceless gift an attractive invitation to learning? In short, even with the best will in the world is it still true to say that "the advancement of knowledge is a prime duty of a university" to be written into the contract of service of each and every staff member irrespective of whether it is good or bad, likely to enliven or deaden his teaching and understanding of the subject? There are many students whose motivation is weakened by the feeling their teacher ranks his teaching of them lower in priority to the research which he hopes will lead to his promotion.

A close examination of what these critics are saying shows that they are not, in fact, rejecting the need for research. Research is essential for university teaching. The criticism is about the type of research and the purpose for which it is done. The criticism really is that much (but not all) research has little relevance to what is taught in university courses and that such research takes up time which could better be used in the improvement of teaching.

The basic complaint is of the verbal sleight-of-hand which treats publication as a synonym for research. All teachers are obliged to have a mastery of the subject which they teach or, at least, to be working steadfastly towards it. ${ }^{13}$ Such a mastery can be obtained only by research. In doing this research, teachers will need to read widely, perhaps to do some empirical study, to talk with others and to think deeply about the subject for 
themselves. They need to bring the results of their research together, put them into order, record them Personality and teaching technique are no substitute for scholarship. It is worth recording that surveys show that students, despite all their concern about presentation and technique, rate mastery of the subject as the most important quality of the good teacher. ${ }^{14}$

The Editor of the Journal of Legal Education has stated the relationship between research, teaching and publication in this way: ${ }^{15}$

The primary function of a law faculty is to bring to students a mastery of the law in society, presented in an imaginative, enthusiastic and inspiring fashion. It is doubtful whether this can be accomplished absent the pursuit of scholarship by every teacher. The product of scholarship may never be set forth in writing; it may be written in myriad forms including but not limited to law review articles, books, briefs, supplementary or complete teaching materials, faculty papers or memoranda. But scholarship there must be if the reasonable expectations of the student are to be met. The student reasonably expects that the "professor" standing before him is a genuine master or, at least, that the professor is moving rapidly in that direction. The student reasonably expects that the professor is bright, imaginative and enthusiastic and that he directs his principal efforts to the necessary reflection on his area so that he may bring to the student a unique contribution on a workaday basis in the classroom. This is the primary value of scholarship. If it finds its way into published form and assists lawmen to administer justice and settle the law in a given area, another important value is added. Finally, if it enhances the reputation of the teacher and his law school, an incident benefit is reaped. But, again, the primary value cannot be ignored. If one "perishes", it should be because he is not fulfilling the reasonable expectations of students. On this basis, perhaps the wonder is that more have not perished.

The best evidence that teachers have done the research necessary for their teaching will be found in the classes which they give. Unfortunately, the university authorities have not routinely looked into the classroom in order to discover whether or not this necessary research has been undertaken. Rather they look to publications as the proof of research. What they fail to acknowledge is that the sort of research which is most readily published is not necessarily the sort of research which is mot helpful to teaching.

This is particularly true with regard to law subjects. In so far as they are concerned with the content of compulsory courses in particular, law teachers wish to illustrate the general principles of their subject. In most cases, the topics which they consider to be important enough to warrant emphasis in their courses will also be the topics which are

14 (1975) 18 A.C.U. Bulletin of Current Documentation 5-6.

15 Murray, op cit. 
emphasised in similar courses throughout the Common Law world. Teachers can do a lot of research on these major teaching topics without any certainty that they will end up with an article which they will get published. There are three reasons for this. First, since a lot of competent teachers will have done research on the same topic, only the very best articles will be published. A teacher can avoid this competition by doing research in areas which other people have not written about. Unfortunately, these other areas may not be important and/or may have no direct relevance to the teacher's courses. Secondly, even if the teacher comes up with a very good article, it may not be published simply because the market has already been pre-empted by other articles, albeit of lesser quality.

Thirdly, publication of the results of his or her research may interfere with the teaching aims of the researcher's own course. This point is dramatically illustrated in a recent book in which a law student describes his first year at Harvard Law School. ${ }^{16}$ The teachers generally used some form of the socratic or case method of teaching. The aim of this method was to stimulate the students to work out their own answers to the problems posed by the teacher. After a while, many of the students discovered they could avoid part of this task in one of the subjects by reading the textbook which the teacher himself had published but not prescribed for the course. The academic's research had been essential for his teaching. The publication of that research detracted from his ability to achieve his teaching aim.

If it is to adopt the programme advocated in this paper, the law school needs to consider carefully both the form and volume of research which it wishes to encourage. It could not, of course, adopt the attitude that no publications are relevant to teaching. Nor should it suggest that law teachers should never write anything unless it can be used in law courses currently taught in their own university. What it must recognize however is that if it places too much emphasis on publication then it may be encouraging a form of research which does not help teaching. Striving for publication may divert research activity away from topics covered in courses and not towards them A pre-occupation with publication has other disadvantageous effects on teaching. It takes up time which might otherwise be spent on course work. It may divert teachers from thinking more about the educational goals which they have for their course, the methods by which they can relate material discovered by research to their course goals, or the way in which material may be better presented in lectures and tutorials. Writing for publication may leave them insufficient time for making innovations in teaching or the setting of assignments, or for putting full comment on written work submitted by students or for making themselves available to individual students for informal discussion. 


\section{B Publish or Perish}

A former President of the New Zealand Court of Appeal has made a scathing criticism of the volume of publications coming from our law schools. He sees this as a: ${ }^{17}$

... development in the functions of law teachers which has obtained quite a new emphasis in the last decade or two. In itself it is to be warmly welcomed, for it is indicative of a new dynamism in legal education which was sadly absent from the rather duller type of scholarship which was once thought sufficient for the education of the law student. But the rat-race has invaded the Universities, and what had its origin in a praiseworthy desire to do a decent job of legal research collateral with the teaching involved in his position, has in some Universities involved the junior lecturer in a frantic necessity to publish, publish, and publish again, even if he has nothing much to say, and what he has be not particularly sound.

With respect, it may be doubted that there is established in Victoria's law school a "publish or perish" syndrome which is anywhere near as advanced as the learned judge suggests. Nevertheless, many teachers believe that it is easier for a well-published academic to get an appointment or promotion than it is for someone who has put the greater proportion of his or her energies into teaching. As a generalization this is probably true even though appointments and promotions committees at Victoria do attempt to take account of teaching ability.

There are two reasons why these committees do not give as much recognition for teaching ability as they should. First, and most important, the committees do not usually have the best evidence on the teaching ability of individual members of staff. In so far as they refer to teaching ability, the references placed before such committees are usually based on the applicant's general reputation as a teacher rather than on first hand observations. It must be acknowledged that members of staff may enjoy a considerable reputation among their colleagues for their teaching ability. This reputation may derive from a number of things: their contribution to formal and informal discussions about teaching; the opinions of those who share the lecturing or tutoring in their subjects; informal comment from students; seeing assignments, examinations, tutorial programmes and other written material which they distribute to their students and the quality and style of their published writings. Such reputations should not be rejected as founded on nothing more than mere staff club gossip. But they are not the best evidence of teaching ability. Appointments and promotions committees would find it easier to give greater weight to teaching ability if the opinions which they received were based on first hand observations of teaching in the classroom and on a reliable survey of student opinion.

17 Turner "Changing the Law" (1969) 3 N.Z.U.L.R., 404, 408. 
The second reason why appointments and promotions committees may emphasise publication at the expense of teaching is that the attitude of the university as a whole to the respective importance of teaching and research is still in the process of changing. While they give an intellectual assent to the importance of teaching, many academics have not yet achieved that same degree of emotional conviction about its importance as they have about publication. To say this is not to suggest anything hypocritical or sinister in the attitude of appointments and promotions committees. Nevertheless, these committees do tend to be rather more suspicious of opinions about an applicant's teaching ability than they are about publications. Assessments of teaching ability are sometimes thought to be more subjective. To a large extent this criticism is a reflection of the belief that those expressing opinions about an applicant's teaching ability do not have an adequate volume of first hand knowledge of the applicant's performance in class. If teaching ability is too often praised by those who have not seen it, then publications are too often praised by those who have not read them. This leads to the jibe that publications do not have to be read; it is enough that they can be counted. In any case, provided that they are based on an adequate sample, opinions about teaching ability need be no more subjective or idiosyncratic than opinions about the quality of publications.

If the universities in general, and the law schools in particular, were properly to set about ensuring that they discharged their teaching obligations, then as an inevitable byproduct the appointments and promotions committees would receive better evidence of the teaching ability of applicants and would be more willing to recognise it. It must be stressed that the programme for improving teaching advocated in this paper is worthwhile in itself. Its prime function is to improve teaching, not to assist teachers to get promotions. Nevertheless, if the latter be only a by-product of the former then it is still a most important by-product. If academics are to be convinced that teaching is worth extra time and trouble, they must not only be told that the university thinks it is important, they must also be shown that it is so.

It is both unrealistic and unfair to expect academics to be unconcerned about the salary they receive or the status accorded them by the university. So long as the university is obliged to divide its staff into hierarchies, it is inevitable that academics will feel encouraged to concentrate on those activities which are most likely to enable them to progress up the hierarchy.

Under the programme now advocated, the law school should be able to reduce the present emphasis on publication. Staff could be encouraged to do research directly related to their courses and to lend their active support to an improvement in the Faculty's whole range of teaching without concern that their career prospects would be harmed. 


\section{Appointments}

It is, of course, one thing to state what you want, it is another thing to get it. In the case of applicants from overseas, an appointments committee is almost entirely dependent on references for any information about their teaching ability. To some extent this problem can be reduced if the university would arrange for prospective appointees to be interviewed by some person who is familiar with the law school's teaching aspirations and can both inform the applicants of them and ascertain their attitude towards them However, notwithstanding the advantages of a properly conducted interview, the problems are sufficiently great to justify Victoria's adopting a system whereby new appointees are not normally granted tenure until they have served a probationary term of two or three years. Given the advantages which tenure confers on the teacher and the disadvantages for the university in having to keep on a sub-standard teacher for the rest of his academic life, this does not seem to be an unreasonable requirement. This is a highly contentious issue. A discussion of it is beyond the scope of this paper. One point can, however, be made.

Obviously a system of tenure can only be successful if the university takes effective steps to find out how well appointees teach once they have taken up their duties. This difficulty can be overcome if the law school adopts a comprehensive programme to improve teaching ability.

\section{$D$ The University's Training Programme}

Having recruited staff interested in teaching, the next step to be taken in improving teaching in the law schools would be to ensure that all teachers should have some initial training in teaching methods. This is not, of course, a need peculiar to law schools. The argument that university teachers do not need any training can be rejected out of hand. Anyone who has studied at university has to a greater or lesser extent suffered from substandard teaching. Also unworthy of serious consideration is the argument that university teaching is an art which cannot be taught - "You've either got it or you haven't". If opera singers can be taught to sing better, and olympic sprinters can be taught to run faster, then university teachers can be taught to teach better. The fact that many university lecturers teach very well is no justification for saying that it is only at the tertiary level of education that teachers do not need training.

The role of the university's Teaching and Research Centre and the resources afforded to it are matters which the university, and not the law school, decide. However, the law school can and should contribute to the discussions which precede the university's decision.

The law school might advocate that a university Teaching and Research Centre should be given sufficient resources to enable it to run an introductory course on teaching for all new members of staff who lack previous teaching experience. A course lasting five to ten full days might well be adequate. In addition, during their first year or so, new staff should 
have several meetings with a member of the Centre to discuss problems they have encountered and other matters. Apart from these general courses, the Teaching Centre should also be able to provide assistance to the law school's own internal teacher training and refresher courses.

While a general university teacher training centre can be of great assistance to law teachers, it is axiomatic that the primary obligation for improving law teaching rests with the school itself.

\section{E Time Release}

One of the difficulties relating to discussions about teaching is that often teachers fail to bring to them the sort of detached analytical rigour which they display in their own academic work. Hunches are treated as established facts. There is no great willingness to do research into published writings on teaching or to do empirical research into the practices which prevail in the law school itself. This is unfortunate. Those who believe that they can develop analytical skills by straight lecturing might be chastened by some of the findings of educationalists. ${ }^{18}$ Empirical research based on the examination papers recently set in the law school might reveal that although law teachers pride themselves on setting questions which require analytical skills, most so-called "problem" questions are little more than essay questions in disguise.

The most likely way in which the law school will get these two kinds of research done and related to its specific needs will be by seconding one of its teachers for a term or two to the university's Teaching and Research Centre or Education Department. This teacher would have no teaching responsibilities during that period. His sole task would be to do the research. He would have the cooperation of the Research Centre or Education Department. The university would need to provide sufficient funds to enable the school to hire a temporary teacher to teach the courses of the person seconded to the Centre. ${ }^{19}$

\section{CONCLUSION}

This paper does not express any radical or original ideas. For the most part, it keeps close to what has been done from time to time or at least accepted as desirable in this law school over the last decade. The latter experience does, however, demonstrate the need for the law school to commit itself to a systematic programme for the review of courses and teaching. Without such a system improvement can only be piecemeal and sporadic.

18 Bligh What's the Use of Lectures? (Penguin, 1971) 18-19, 32-33.

19 Proposals to provide for such a system of time release are currently being considered by the university authorities at Victoria University of Wellington. 